\title{
Complejo Trichophyton mentagrophytes
}

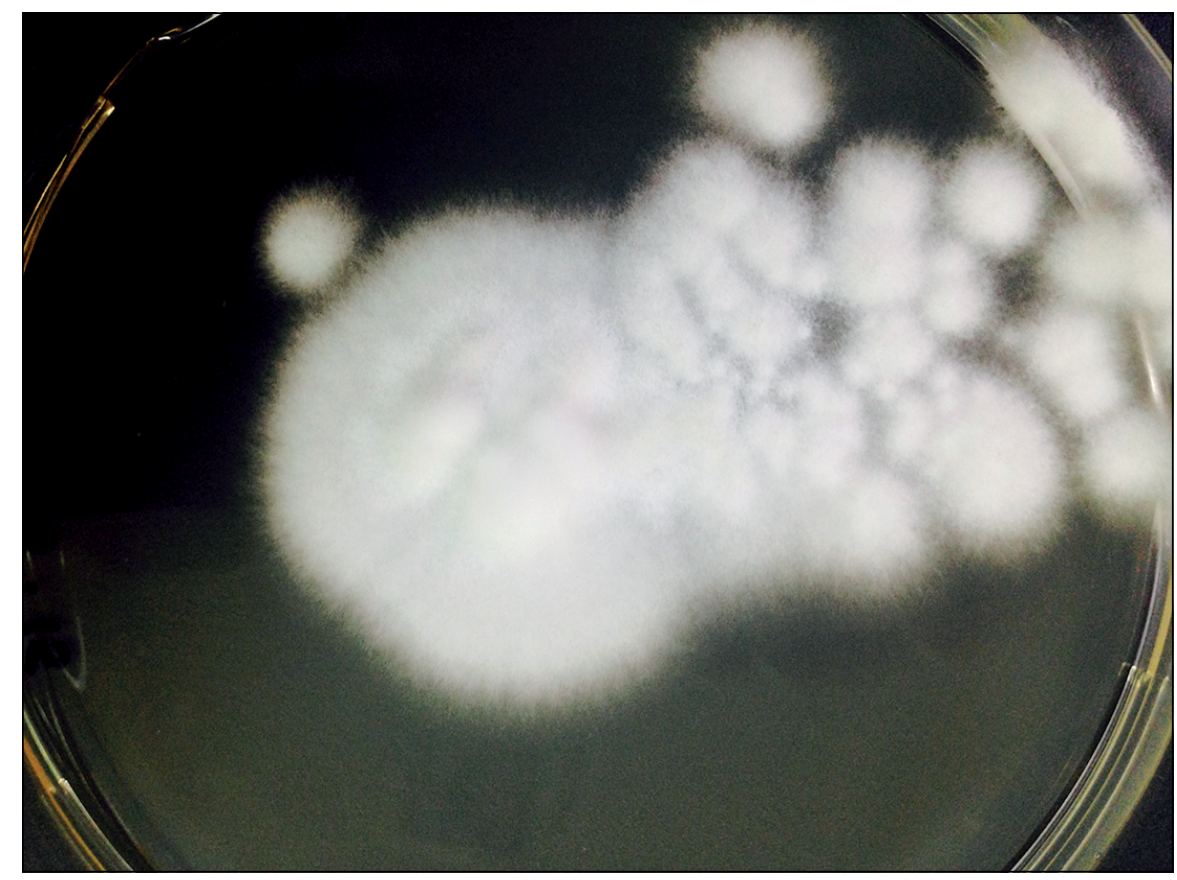

Figura 1. Cultivo de Complejo T. mentagrophytes incubado en agar Saboureaud glucosa, a $30^{\circ} \mathrm{C}$ por 7 días (Laboratorio Dr. Eduardo Alvarez, U. de Chile).

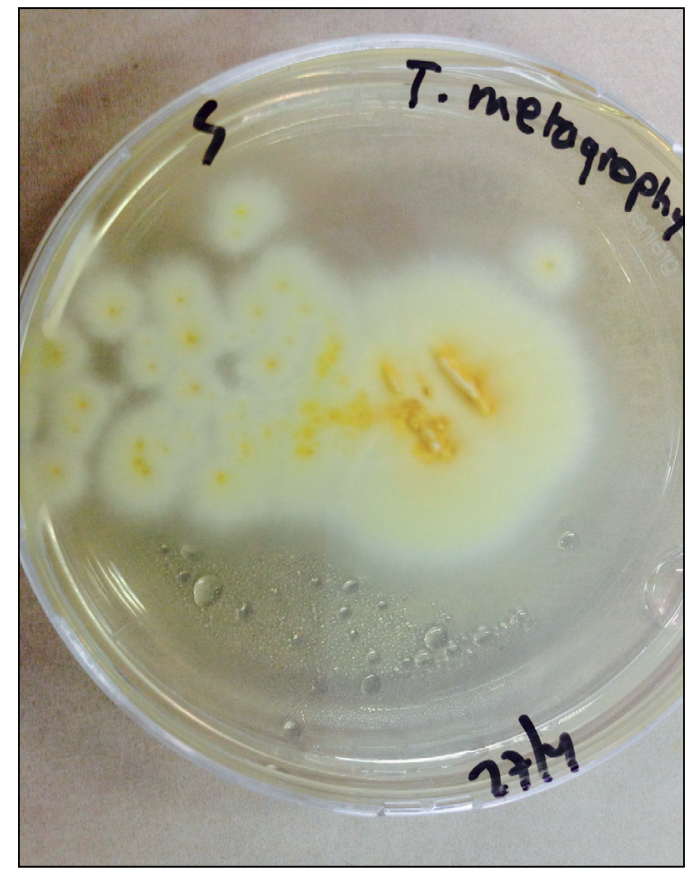

Figura 2. Reverso de cultivo de Complejo T. mentagrophytes incubado en agar Saboureaud glucosa, a $30^{\circ} \mathrm{C}$ por 7 días (Laboratorio Dr. Eduardo Alvarez, U. de Chile).

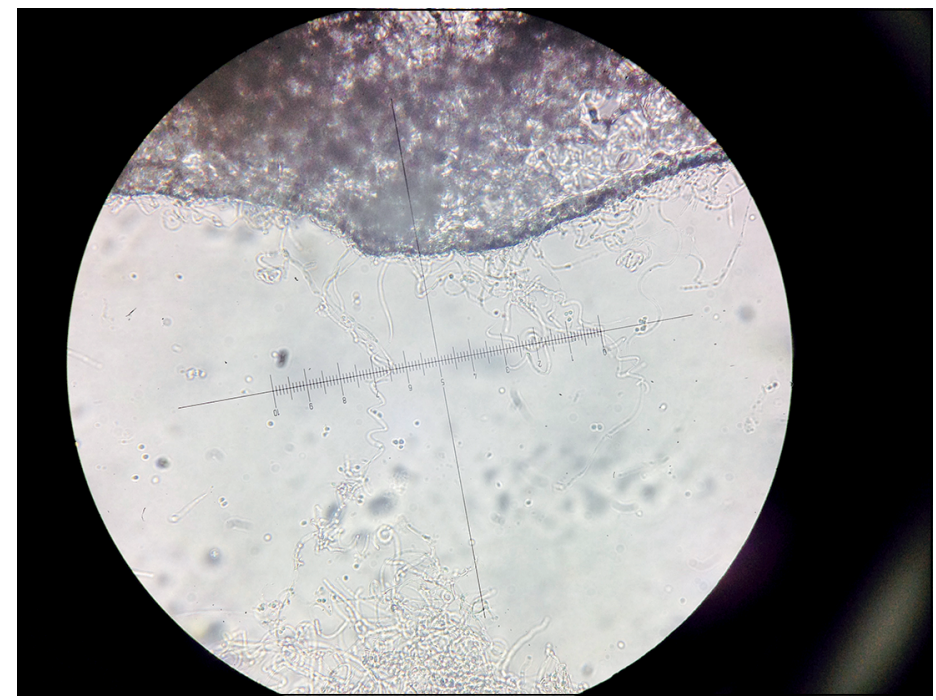

Figura 3. Imagen microscópica de cultivo de Complejo T. mentagrophytes incubado en agar Saboureaud glucosa, a $30{ }^{\circ} \mathrm{C}$ por 7 días, se observan hifas espiraladas y abundantes microconidios esféricos o semiesféricos. (40X). (Laboratorio Dr. Eduardo Alvarez, U. de Chile).

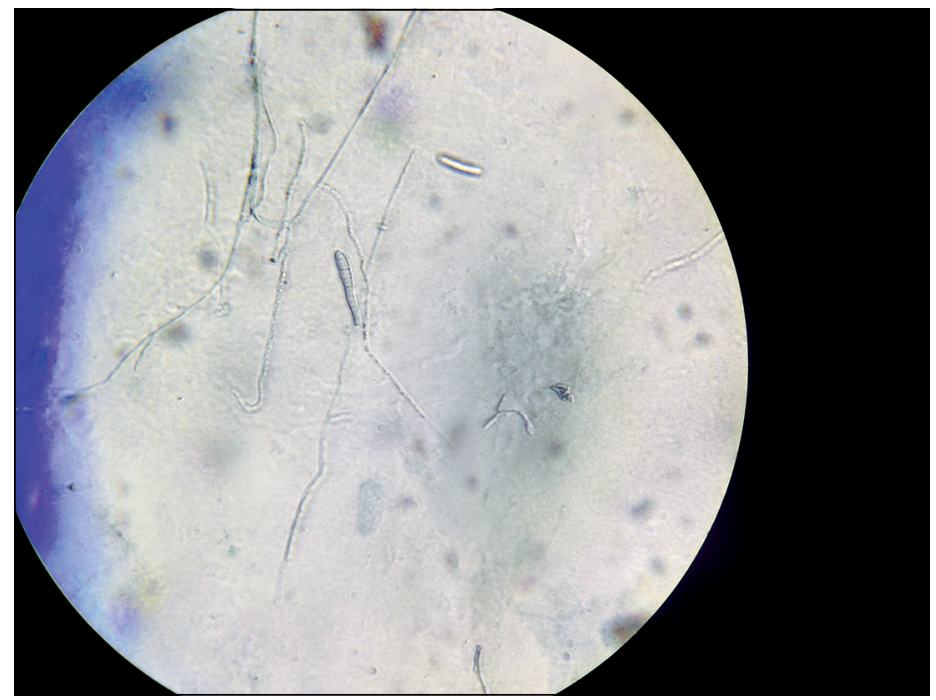

Figura 4. Imágenes microscópicas de cultivo de Complejo T. mentagrophytes incubado en agar Saboureaud glucosa, a $30^{\circ} \mathrm{C}$ por 15 días, se observan macroconidios en clava teñidas con tinta china. (40X). (Laboratorio Dr. Eduardo Alvarez, U. de Chile). 


\section{Complejo Trichophyton mentagrophytes}

El complejo Trichophyton mentagrophytes es un grupo de hongos filamentosos hialinos septados y queratinolíticos, perteneciente a la familia Arthrodermataceae. Este grupo de hongos comprende tres especies relacionadas: Arthroderma benhamiae/Trichophyton erinacei, Arthroderma vanbreuseghemii/Trichophyton interdigitale y Arthroderma simii/Trichophyton mentagrophytes-Trichophyton sp (forma sexual/asexual, respectivamente). Estas especies pueden identificarse mediante la técnica de análisis de secuencias de la región espaciadora interna transcrita (ITS) del ARNr, no así por técnicas convencionales, ya que las características macro y micromorfológicas de las colonias son altamente pleomórficas.

El complejo T. mentagrophytes es el segundo agente etiológico aislado en dermatofitosis de piel y uña en humanos y animales. Trichophyton erinacei, T. mentagrophytes y Trichophyton sp. se aíslan principalmente en lesiones de piel, pelo y uñas de animales tales como erizos y roedores; y con menor frecuencia se aíslan en lesiones de piel, barba y cuero cabelludo de trabajadores rurales. Por su parte, T. interdigitale es el principal agente asociado a dermatofitosis humana, causando con mayor frecuencia tiña pedis crónica (particularmente de tipo vesicular) y con menor frecuencia, tiña corporis y onicomicosis.

El diagnóstico de laboratorio se realiza a partir del cultivo de muestras de raspados o fragmentos de la lesión. La identificación es fundamentalmente convencional basándose en observaciones macro y micromorfológicas de las colonias y pruebas bioquímicas y fisiológicas. El complejo T. mentagrophytes cultivado en agar Sabouraud glucosa entre 6-7 días a $25-30^{\circ} \mathrm{C}$, presenta colonias generalmente planas, de color blanco o crema, con textura pulverulenta, granulosa o aterciopelada (Figura 1) y al reverso se observa con pigmento amarillento (Figura 2) o café rosado a rojo café. Microscópicamente se observan hifas hialinas, septadas y ramificadas, abundantes microconidios esféricos o semiesféricos, los cuales se producen solitariamente a lo largo de la hifa o en acúmulos que semejan racimos de uvas; esta disposición, así como la ramificación de los conidióforos en ángulo recto, es característica. También pueden observarse clamidoconidios esféricos, hifas en espiral (Figura 3), en raqueta y cuerpos nodulares. Los macroconidios presentan una pared delgada, en clava y son multiseptados (Figura 4).

La hidrólisis de la urea en 5 a 7 días es variable. Todas las cepas presentan perforación de pelo positiva en aproximadamente 14 días y alcalinizan el medio púrpura bromocresol-leche-glucosa en aproximadamente 7 días. Mediante estas dos últimas pruebas es posible diferenciarlo de T. rubrum, otro agente causal de dermatofitosis.

Un estudio de susceptibilidad del complejo T. mentagrophytes, realizado en nuestro país, demostró susceptibilidad a fluconazol, itraconazol, clotrimazol, griseofulvina y terbinafina. Aunque griseofulvina y terbinafina no disponen de valores de punto de corte de CIM, se obtuvieron CIM para estos dos antifúngicos muy por debajo de la concentración alcanzada en piel.

\section{Referencias bibliográficas}

1.- Díaz Jarabrán M C, Díaz González P, Espinoza Rodríguez J, Carrillo Muñoz A J. Evaluación del perfil de susceptibilidad in vitro de aislamientos clínicos de Trichophyton mentagrophytes y Trichophyton rubrum aislados en Chile. Rev Iberoam Micol 2015; 32: 83-7.

2.- Nenoff P, Herrmann J, Gräser Y. Trichophyton mentagrophytes sive interdigitale? A dermatophyte in the course time. J Dtsch Dermatol Ges 2007; 5: 198-202.

3.- Ates A, Ozcan K, Ilkit M. Diagnostic value of morphological, physiological and biochemical test in distinguishing Trichophyton rubrum from Trichophyton mentagrophytes complex. Med Mycol 2008; 46: 811-22.

Lina Rivas

Magíster en Ciencias Biomédicas, mención en Microbiología, Universidad de Chile.

Margareta Mühlhauser

Laboratorio de Microbiología, Hospital Dipreca.

Versión in extenso disponible en www.sochinf.cl

Correspondencia a:

|rivas734@gmail.com 